\section{Colombia: new plan imperils Amazon}

The Colombian government approved a new National Development Plan in March that could increase the country's deforestation to 280,000 hectares annually from 2018 to 2022 . As well as flying in the face of expectations for socioeconomic and environmental improvements after Colombia's armed conflict ceased in 2016, this plan has implications beyond Colombia.

The northwest region of the Amazon is the wettest, so the increase in deforestation stands to destroy the water cycle of the whole basin and therefore the entire Amazonian ecosystem. As far as we know, the government has no plans to control this exploitation of resources.

Such misuse of land will continue unabated, particularly in rural areas where biodiversity is richest, until environmental policies are reformed, state control is enforced and society has a voice in decisions and in policymaking.

Dolors Armenteras, Thomas Defler National University of Colombia, Bogotá, Colombia. darmenterasp@unal.edu.co

\section{One million species to go extinct - again}

It is less than 20 years since we last woke up to headlines proclaiming that 1 million species will become extinct (see R. J. Ladle et al. Nature 428, 799; 2004). Almost identical headlines are now being generated across the world by the release of the summary of the global assessment report of the Intergovernmental SciencePolicy Platform on Biodiversity and Ecosystem Services (IPBES) (see go.nature.com/2v4zbn9). Although many conservationists will be glad of the publicity, it risks detracting from the more detailed findings of this important report when it is published later this year.

In both cases, the extinction figure is an extrapolation based on predicted, rather than documented, species richness. Such headlines are easy targets for the anti-environmentalist lobby and so could undermine the credibility and legitimacy of the report and of conservation science in general.

The doom and gloom of the report summary is intended to mobilize conservation action (see N. Knowlton Nature 544, 271; 2017). But the more often such claims are made, the more likely they are to be met with apathy. What we need is a more nuanced use of extinction rhetoric, one that aligns scientific evidence of documented and predicted extinctions with cultural frames, institutional frameworks and organizational interests.

Richard J. Ladle Institute of Biological and Health Sciences, Federal University of Alagoas, Maceió, Brazil. richardjamesladle@gmail.com

\section{Dam's stark threat to world's rarest ape}

The Tapanuli orangutan (Pongo tapanuliensis) is the rarest great ape species on Earth. Fewer than 800 individuals remain on the Indonesian island of Sumatra, where the species is declining further from deforestation and hunting. The apes are already split into three populations, and the proposed development of a hydroelectric dam on the river that connects these groups could obliterate the species.

The dam construction will increase deforestation, inundate tracts of land and generate 20 kilometres of access roads and 14 kilometres of transmission lines. This will render two of the ape populations non-viable. Although the Indonesian government is proposing mitigation measures, the scientific consensus is that nothing can offset the negative impacts on the species (see S. A. Wich et al. Conserv. Sci. Pract. http://doi.org/c5tx; 2019).

Indonesia seems to be facing a stark choice: a dam for energy security versus the survival of an ape species.

Erik Meijaard Bandar Seri Begawan, Brunei Darussalam, Borneo.

emeijaard@gmail.com

\section{Risks of replenishing China's groundwater}

There could be unintended consequences of ambitious efforts to stem the depletion of nonrenewable groundwater resources in the North China Plain (see also E. K. White Nature 566, 326; 2019). The plan is to recharge groundwater, limit extraction and impose water-conservation measures. Recharging must be gradual, however, if it is not to incur risks. In our experience, rapid recharging can cause groundwater tables to rise by more than 20 metres within a few weeks.

Such a rise could create sudden stress changes in soil formations, threatening buildings and infrastructure. The water could be exposed to the pervasive organic contaminants and heavy metals that have polluted China's soils over the past half-century (Nature 566, 26-29; 2019). Also, carbon in soil is a major terrestrial source of carbon dioxide and is sensitive to moisture changes.

In our view, the North China Plain project needs cautious stewardship to offset these risks. It should involve the Ministry of Ecology and Environment (the body responsible for groundwater quality and adapting to climate change), alongside the other ministries that are co-sponsoring the action plan.

David O'Connor, Deyi Hou Tsinghua University, Beijing, China.

houdeyi@tsinghua.edu.cn

\section{Stats: don't retire significance testing}

I contend that there is a better way to correct the misuse of tests for statistical significance than by dispensing with them altogether (see V. Amrhein et al. Nature 567, 305-307; 2019).

The 'error-statistical perspective' described by Deborah Mayo provides valuable insight into tests of significance and other frequentist concepts (see Statistical Inference as Severe Testing: How to Get Beyond the Statistics Wars; 2018). It stringently evaluates statistical hypotheses by using different statistical methods and their error probabilities, and by ruling out erroneous interpretations of data.

This approach is principled, whereas that of Amrhein et al. is pragmatic - in that it recommends a linguistic reform. In my view, the error-statistical perspective better advances the discussion and application of statistical significance testing than debating whether we should curtail application of a popular statistical expression.

Brian Haig University of Canterbury, New Zealand brian.haig@canterbury.ac.nz

\section{Stats: try caveat lector, not petition}

Notice of the demise of the $P$ value might or might not be premature, but I would respectfully query the justification for 800 signatories on the $P$-value death warrant (V. Amrhein et al. Nature 567, 305-307; 2019).

Iconic dichotomies are here to stay. And we have access to the electoral process (whereby the winner has more than $50 \%$ of the vote) and jurisprudence (whereby $51 \%$ certainty is the criterion for approving a scientific expert opinion), as well as to "the quick and the dead" (excluding Schrödinger's cat).

The burden of ratifying the conclusions of a paper should continue to fall on the reader's perspicacity - caveat lector as further informed by your Editorial (Nature 567, 283; 2019). Frederick E. Lepore Rutgers Robert Wood Johnson Medical School, New Brunswick, New Jersey, USA. leporefe@rutgers.edu 